\title{
Will the benefits of classical biological control be lost in the
}

\section{"biotechnology stampede"?}

Biological control is the use of parasites, predators and pathogens to reduce pest populations to lower levels than would otherwise occur. It is a successful method of pest control that has been used for over a hundred years since the successful control of cottony cushion scale in California by the vedalia beetle in the $1880 \mathrm{~s}$. Commercial pest control success has been achieved using biological control methods in at least 253 projects around the world. An analysis by Paul DeBach of the University of California at Riverside showed that for each dollar invested in biological control in California, $\$ 30$ was saved through lower crop damage and reduced chemical control costs. The total savings in California alone exceeded $\$ 200$ million by 1970.

With such a success record, and with the high cost of competing approaches (e.g., \$15-20 million to develop one pesticide, with an expected life of five to ten years), it is a ringing indictment of our priorities for the allocation of resources that biological control has been attempted for only 5 percent (223/ 5000 ) of the insect pest species recorded worldwide. Clearly, biological control has been underutilized. Overshadowed by chemical pesticides since the $1950 \mathrm{~s}$, it is now losing more ground to the glamour of biotechnology. Genetically engineered microbes or resistant plants are currently seen as a possible "new generation" of pest controls of great promise. However, there are large costs associated with this as yet unproven approach. Like other control strategies, pest controls based on genetically modified organisms are likely to be of value in specific cases, but will not be a panacea. Yet in the rush by the USDA and the entomology departments in land grant universities to create biotechnology centers, support for classical biological control has seriously diminished. Positions are being lost. Classical biological control specialists are being reassigned to other duties. Laboratory budgets and staffing are being drastically cut. The truism that what you get out depends on what you put in is certainly true for biological control. We cannot simultaneously allow biological control's infrastructure (positions, agency focus, funding) to be eliminated and also expect to reduce U.S. agriculture's dependence on chemical pesticides. Biotechnology has yet to control its first pest; classical biological control has worked for 100 years and yet its potential has barely been touched. Clearly, one of the best ways to control pests without using pesticides is to use biological control methods.

Biological control can take three principal forms:

Conservation: Where effective native or previously imported natural enemies are already established, biological control functions by protecting them. Harmful chemicals are avoided, and other practices, such as plowing, use of ground covers, and timing of irrigation, are adjusted so that they aid rather than interfere with the action of biocontrol agents. But first we must know which actions are effective. This requires that we maintain a core of university and government research scientists to define these techniques and adapt them to ever-changing cropping practices.

Importation: When effective natural enemies do not occur locally, biocontrol functions by finding agents in other locations (often foreign countries in the case of exotic pests) and introducing them where needed. This is the heart of classical biological control, and it has proven successful in hundreds of cases. However, importation of new species must be done either by the USDA or by state facilities authorized by the USDA, since harm can be done by careless movement of plants and animals by non-specialists. Biocontrol importations cannot be undertaken by the private sector, nor can their benefits be packaged and sold, since once a successful parasite or predator is established it spreads under its own power to new locations. Clearly, the universities, state agencies and the USDA have a crucial role in maintaining well-equipped quarantine and field laboratories and adequate staffs of foreign collectors.

Augmentation: For species to be used indoors, such as in greenhouses, or for those whose populations cannot survive from year to year, biocontrol functions through the artificial production of beneficial species in government or commercial insectaries. The use of Encarsia formosa for control of greenhouse whitefly is but one successful example. Typically, larger than natural numbers are reared and released to overwhelm pest populations (as with use of Trichogramma spp. wasps). Creation and maintenance of such mass rearing facilities, while of less importance to biological control than adequate support of importation facilities, is needed for some pest species.

How U.S. entomologists dealt with two pests, the alfalfa weevil and the Colorado potato beetle, offers an interesting contrast. For the first pest, state and federal agencies began biological control efforts early and pushed them vigorously, ultimately solving the problem. In the second case, a prolonged and costly series of temporary solutions was developed based on chemical pesticides, with little serious effort in the U.S. to utilize biocontrol agents.

continued on page 96 
governing the applications of farm chemicals, and even authority for addressing pesticide contamination of ground water is unclear in some states.

\section{Getting from here to there}

Perhaps the major questions raised by the report lie in the relationship between the current problems and the future projected situation. What will the path from here to there be like?

The report hazards a few clues about the USDA viewpoint. "Reducing the direct costs of production needs to be a primary object of all U.S. farmers who wish to participate in or find themselves dependent upon world markets," the introduction says. That comment, combined with the projection that the millions of acres coming out of production will do so because of cost competition in a climate of limited demand, may augur for a USDA policy of support for low-input farming methods.
Methods to prevent pollutants from being created in the first place by limiting the availability of nutrients to runoff are also positively endorsed in the report. "Management practices are flexible and relatively low in cost," the report comments. Regional cooperation on nonpoint pollution which is an interstate problem is also suggested.

\section{Unanswered questions}

Overall, however, many fundamental questions remain unaddressed by the report. Are the directions of cost-cutting and pollution control possible through reduction of synthetic pesticide and fertilizer use on croplands compatible with the increased yield projections given in the preferred scenario? What is the likely structure of the farming community in this high technology future--will farms continue to grow in size, as predicted by the 1986 report from the Office of Technology Assessment, so that the turn of the century will see 50,000 huge farms producing most of the nation's food and fiber? What is the likely response of the farm community to the projection that cropland needs will decrease significantly because of technological advances--and will that response affect the direction? Further, is it safe to ignore the possibility of a gradual "greenhouse" effect, now widely predicted by scientists to be underway? And--should the USDA scenario come to be--what are the plans for transitioning rural peoples, communities, and regions to such a radically different agricultural future? What does the scenario imply for the USDA itself as an agency and for its resourcerelated programs such as the Soil Conservation Service and the Extension Service?

In the face of such questions it is clear that many more voices are needed to suggest a reasonable path toward a viable and healthy future for the American farm community.

\section{OPINION-continued from page 50}

The alfalfa weevil was introduced accidentally from Europe into the eastern U.S. in the 1950 s. By the 1960 s it was a severe pest of alfalfa throughout the region, causing millions of dollars of losses in reduced yield and required pesticides. Virtually every acre was likely to be treated at least once in most years. In the 1960 s and 1970s the USDA, in cooperation with various land grant universities, conducted a parasite introduction program aimed at establishing species of European parasites specific to the pest, especially the euphorine braconid wasp Microctonus aethiopoides Loan and the ichneumonid Bathyplectes anurus (Thoms.). By the late 1970s the problem in the eastern U.S. was solved. Losses and spray requirements plummeted. Annual savings in the northeast alone now exceed $\$ 882,000$.

The Colorado potato beetle (CPB), a native species, has severely damaged U.S. potato crops since the late nineteenth century. From 1920 on, a series of insecticides was developed for use against this pest. One insecticide succeeded another as older materials became ineffective because of pest resistance. By the 1980s control became virtually unattainable in some areas. The high cost of sprays severely reduced profits. Wells were contaminated by residues of insecticides such as carbofuran and aldicarb. The problem was not solved by 60 years of chemically-oriented research. Currently, biocontrol is being vigorously pursued for the first time in the U.S. Preliminary results in Massachusetts and elsewhere strongly suggest that growers will be able to convert from current intensive use of chemicals to programs based on utilization of native and exotic natural enemies combined with the recently discovered bacterial pesticide, Bacillus thuringiensis var. "San Diego," which is effective against young CPB larvae but harmless to coccinellids and other beneficial insects in potato fields.

Biological control will produce results in direct proportion to the support and attention it receives. It is the best, most proven and most economical way to solve pest problems. To prosper, it needs support within the USDA and our land grant universities in the form of positions and grant support for projects and staff. Biocontrol does not have biotechnology's glamour. No one remembers costs they no longer have to pay, and so biocontrol successes are soon forgotten. To foster a U.S. agriculture less dependent on insecticides, we must find ways to create both financial and moral support for biological control, a proven technology. As universities and the USDA rush to embrace biotechnology, their neglect of biological control seriously threatens to make a poor situation worse.

R. G. Van Driesche and D. N. Ferro, Department of Entomology, University of Massachusetts, Amherst, Massachusetts 01003 